\title{
Differential Effects of Growth Hormone and Alfa Calcidol on Trabecular and Cortical Bones in Hypophysectomized Rats
}

\author{
AFSHAN A. CHAUDHRY, MARIANO CASTRO-MAGANA, JOHN F. ALOIA, AND JAMES K. YEH \\ Department of Pediatric Endocrinology [A.A.C., M.C.-M.], Department of Medicine [J.F.A., J.K.Y.], Metabolism Laboratory [J.K.Y.], \\ Winthrop University Hospital, Mineola, New York 11501
}

\begin{abstract}
Growth hormone $(\mathrm{GH})$ deficiency in children causes severe growth retardation, vitamin D deficiency, and osteopenia. We investigated whether alfacalcidol (1OHD) alone or in combination with GH can improve bone formation. Forty hypophysectomized female rats $(\mathrm{HX})$ at the age of $8 \mathrm{wk}$ were divided into $\mathrm{HX}, \mathrm{HX}+$ 1OHD (oral $0.25 \mu \mathrm{g} / \mathrm{kg}$ daily), $\mathrm{HX}+\mathrm{GH}(0.666 \mathrm{mg} / 0.2 \mathrm{~mL}$ SC daily) and $\mathrm{HX}+\mathrm{GH}+1 \mathrm{OHD}$ groups for a 4-wk study. Results showed that GH increased body weight, bone area, bone mineral content (BMC), and bone mineral density (BMD), whereas 1OHD only increased $\mathrm{BMC}$ and BMD. In cortical bone, GH increased both periosteal and endocortical bone formation resulting in a significant increase in cortical size and area in percentage, whereas 1OHD suppressed endocortical erosion surface per bone surface (ES/BS) without a significant effect on bone formation rate per bone surface (BFR/ $\mathrm{BS})$. In trabecular bone, GH mitigated the bone loss by increasing BFR/BS, whereas the $1 \mathrm{OHD}$ effect was by suppression of trabecular bone turnover in the HX rats. The combination of $\mathrm{GH}$ and 1OHD had no additive effect on increasing trabecular bone mass. In conclusion, $\mathrm{GH}$ activates new bone formation and increases bone turnover whereas $1 \mathrm{OHD}$ suppresses bone turnover. The combination intervention does not seem to provide any additive benefit. (Pediatr Res 65: 403-408, 2009)
\end{abstract}

$\mathrm{T}$ he main reason to treat children suffering from growth hormone $(\mathrm{GH})$ deficiency with recombinant human $\mathrm{GH}$ is to stimulate the longitudinal skeletal growth. The treatment with GH leads to the normalization of height in majority of these patients, and when the patients have attained adult height GH therapy is terminated. Previous studies demonstrate that $\mathrm{GH}$ treatment alone is unable to fully restore the bone mass and density to normal levels. This result has been demonstrated in the studies of human and hyphophysectomized animal model (1-3). GH has a direct, and an indirect effect on the bone and cartilage development. It has been known for over a decade, that GH induces IGF-I gene transcription in vivo quite rapidly, leading to the sustained production of IGF-I mRNAs and protein. IGF-I in turn stimulates the proliferation of the chondrocytes, resulting in the bone growth. GH directly enhances the proliferation of osteoblasts and increases the new bone formation and also stimulates differentiation of the chondrocytes $(4-6)$.

Received June 17, 2008; accepted November 3, 2008

Correspondence: Afshan A. Chaudhry, Department of Pediatric Endocrinology, Winthrop University Hospital, 401 South Sycamore Ave, Marshfield, WI 54449; e-mail: drafshan@hotmail.com
The biologically active form of vitamin D, called calcitriol, is formed in the mitochondria of the renal tubules by the action of the enzyme $1 \alpha$ hydroxylase on 25 -hydroxy cholecalciferol. The 1- $\alpha$-hydroxylase activity in the kidney is tightly regulated. The major inducers of this enzyme are PTH, hypophosphatemia, and other anabolic hormones. GH also stimulates 1- $\alpha$-hydroxylase enzyme and increases the calcitriol level (7-9). In children with GH deficiency or panhypopituitarism, however, there is a latent deficiency of the active vitamin D (10-12).

Calcitriol directly stimulates osteoblast, osteoclast, and chondrocyte. A vitamin D receptor is present in osteoblast, osteoclast precursors, and has most recently been identified in mature osteoclast. It is also involved in osteoblast differentiation and increases the syntheses of collagen type I and matrix proteins like osteocalcin and osteopontin, which are important for mineralization, functioning, and metabolism of bone tissue. Calcitriol is also a potent stimulator of osteoclastic bone resorption. The function includes stimulating differentiation and fusion of osteoclast progenitors and activating mature preformed osteoclast (13-15).

$1 \mathrm{OHD}$ is an analog of the calcitriol. It does not require renal hydroxylation but requires 25-hydroxylation in the liver for its conversion to calcitriol. It has been widely used in the treatment of a variety of metabolic bone diseases, including renal osteodystrophy, rickets/osteomalacia, and osteoporosis (1617). 1OHD induces an active absorption of calcium and phosphate. It also improves the mineralization of the bones and facilitates a normal neuromuscular functioning. There is some evidence of the anabolic effect of this metabolite on the skeleton (18-21). 1OHD increases the synthesis of IGF-2, transforming growth factor $\beta$ (TGF- $\beta$ ) in osteoblast-like cells (22) and the number of IGF-1 receptors. Hence, by increasing IGF-1 receptors, the action of GH on the bone is enhanced $(23,24)$. Because GH and 1OHD have widely divergent effects on bone formation, the concurrent use of these two agents is likely to have substantial effects on the bone metabolism.

In young rats, HX results not only in the cessation of growth-dependent increase in new bone formation, but also in

Abbreviations: 1OHD, alfa calcidol; Bar, bone area; BFR, bone formation rate; BMC, bone mineral content; BMD, bone mineral density; BS, bone surface; BV, bone volume; ES, erosion surface; HX, hypophysectomized; LGR, longitudinal growth rate; MAR, mineral apposition rate; MS, mineralized surface; $\mathbf{T V}$, tissue volume 
a loss of bone volume. Previously, we reported histologic evidence that the administration of $\mathrm{GH}$ can prevent cortical bone loss; but only partially prevents trabecular bone loss in the tibias of HX rats $(25,26)$. It is important to investigate other agents that in combination with $\mathrm{GH}$ will have a more beneficial effect on the cortical as well as trabecular bone in young HX rats. Many groups have used GH in combination with other anabolic or antiresorptive agents such as estrogen, PTH, and testosterone, but have failed to show adequate improvement in the trabecular bone (27-31).

Previous studies have demonstrated that GH improves bone formation (3). Studies have also shown that 1OHD improves bone formation and prevents bone loss (18-21). The combination of $\mathrm{GH}$ and 1OHD should, therefore, be helpful in restoring the trabecular bone loss. The purpose of this study is to investigate the effect of 1OHD alone, and in combination with the growth hormone, on cortical and trabecular bone in young HX rats.

\section{MATERIALS AND METHODS}

Treatment of animals. Forty female Sprague-Dawley rats were HX at 6 wk of age by the supplier (Hilltop lab Animals, Scott dale, PA) and shipped along with 10 intact rats to serve as the age-matched control group (intact). HX rats were assigned into four groups of 10 animals each by the stratified weight randomization method: $\mathrm{HX}, \mathrm{HX}+1 \mathrm{OHD}, \mathrm{HX}+\mathrm{GH}$, and $\mathrm{HX}+\mathrm{GH}+$ 1OHD groups. 1OHD (Sigma Chemical Chemicals, St. Louis, MO) was dissolved in ethanol and diluted in 1,2 propanediol vehicle to the concentration of $0.25 \mu \mathrm{g} / \mathrm{kg}$ of body weight in $0.1 \mathrm{~mL}$ volume and was administered orally five times a week. Recombinant Human GH was provided by NovoNordisk (Denmark) in a preprepared concentration of $5 \mathrm{mg} / 1.5 \mathrm{~mL}$ for the standard for subcutaneous (s.c.) administration at a dose of $3.33 \mathrm{mg} / \mathrm{kg}$ per day, five days per week.

Throughout the experiment, all HX rats were supplemented daily with hydrocortisone in the form of sodium succinate $(1 \mathrm{mg} / \mathrm{kg} \mathrm{BW})$ and thyroxine at $0.02 \mathrm{mg} / \mathrm{kg}$, s.c. They were also given $3 \%$ sucrose water ad libitum to maintain their blood glucose levels whereas all pituitary-intact rats were given normal tap water ad libitum. All animals were housed under local vivarium conditions (temperature $23.8^{\circ} \mathrm{C}$ and $12 \mathrm{~h}$ on/off light cycle), and allowed free access to a standard pelleted chow diet, which contained $0.93 \%$ calcium, $0.65 \%$ phosphorus, and $3 \mathrm{IU} / \mathrm{g}$ vitamin $\mathrm{D}_{3}$ (Robert Laboratory chow 5001, Ralston Purina, Madison, WI). The body weight of the animals was measured weekly. The duration of experiment was 4 wk. The success of HX surgery was confirmed at the end of the study by observing failure to gain body weight, uterine weight, and a significant reduction in longitudinal growth rate (LGR) of the proximal tibial metaphysis using histomorphometric analysis.

This study was carried out at Winthrop University Hospital (Mineola, NY) and the animals were handled according to the guidelines for care in the use of laboratory animals by National Institutes of Health (National Institutes of Health). The Laboratory Animal Care Committee of Winthrop University Hospital had approved the experiment and protocol.

Preparation of the specimens. Each rat was labeled with calcein at a dose of $10 \mathrm{mg} / \mathrm{kg}$ (Sigma Chemical Chemicals, St. Louis, MO) intramuscularly on the 19th and 26th day of the experiment. The animals were anesthetized with intra peritoneal injection of ketamine $(80 \mathrm{mg} / \mathrm{kg})$ and xylazine $(12 \mathrm{mg} / \mathrm{kg})$ and were euthanized by exsanguination. Both femur and tibia were isolated and preserved. The femur was used for the measurement of bone length, bone area, BMC, and bone mineral density (BMD) by dual energy x-ray absorptiometry using a Hologic QDR-4500A with Delphi upgrade (Hologic, Bedford, MA). The instrument was set in ultra resolution mode, with a line spacing of $0.0254 \mathrm{~cm}$, resolution of $0.0127 \mathrm{~cm}$, and collimation of $0.9 \mathrm{~cm}$ diameter. The BMC and bone area were measured and BMD was calculated as BMC divided by the bone area. The coefficient of variation of these measurements was less than $1 \%$ at our laboratory.

The tibia was used for static and dynamic bone histomorphometric analyses. The proximal tibial metaphysis and diaphysis with the tibia-fibular junction were cut and stained with Villanueva Osteochrome Bone Stain (Polyscience, Warrington, PA) for $5 \mathrm{~d}$. Then the specimens were dehydrated and embedded in methyl methacrylate (EM Science, Gibbstown, NJ).
Cross-sections of the tibial diaphysis just proximal to the tibia-fibular junction were sectioned at $8-\mu \mathrm{m}$ thickness and frontal sections of the proximal tibial metaphysis were sectioned at $5-\mu \mathrm{m}$ thickness using a microtome (Leica RM2155; Leica, Nussloch, Germany) for static and dynamic histomorphometric analyses.

Bone histomorphometric analysis of the tibia. A digitizing morphometric system (OsteoMetrics, Atlanta, GA) was used to measure bone histomorphometric parameters. The following parameters of trabecular bone were measured: total tissue volume (TV), bone volume (BV), bone surface (BS), erosion surface (ES), and single- and double-labeled surface and interlabel width. This data were used to calculate the percent trabecular bone volume (BV/TV), ES/BS, mineralizing surface per bone surface (MS/BS), mineral apposition rate (MAR), bone formation rate (BFR)/BS, in accordance with the standard nomenclature proposed by Parfitt et al. (32). In this study, the region of trabecular bone measured in the $\mathrm{HX}$ rats without $\mathrm{GH}$ treatment was $0.5-3.5 \mathrm{~mm}$ distal to the lower margin of the growth plate in the proximal tibial metaphysis, whereas in the HX rats with $\mathrm{GH}$ treatment and intact group was calculated to be $1-4 \mathrm{~mm}$ distal to the lower margin of growth plate and consists of secondary spongiosa. In addition to the measurement of the above parameters, interlabel width beneath the growth plate was used to calculate the LGR per day. One of the frontal sections of each proximal tibial metaphysis was stained using Goldner Trichrome method to measure the osteoclast cell number, bone area, and bone surface. These data were used to calculate osteoclast cell number per bone area $\left(\# / \mathrm{mm}^{2}\right)$. The adjacent section of each proximal tibial metaphysis was stained using Von Kossa method for photomicrograph.

The measured parameters for cortical bone were the total tissue area, cortical bone area, periosteal and endocortical BS and MS, interlabel width, and endocortical ES. These data were used to calculate cortical area in percentage, and periosteal and endocortical MS/BS, MAR, BFR/BS, and ES/BS.

Statistical analysis. All the data were expressed as means with SD. Multiple comparisons of data among the groups were performed by ANOVA with the Tukey-Kramer test. All statistical analyses were performed using Prism-5.0 program on a Hewlett Packard computer. A significance level of $p<0.05$ was used for all the comparisons.

\section{RESULTS}

Although the intact young animals were growing during the experimental period, HX resulted in a cessation of weight gain, tibial LGR, bone lengthening, bone size in area, a decrease in femoral BMC and BMD, and an atrophy of the uterine in weight (Table 1). GH administration resulted in a significant increase in body weight, tibial LGR, femoral bone length, and bone area, except uterine weight, to the levels not significantly different from those of the age-matched intact group. Although the BMC and BMD of the GH-treated groups increased compared with the HX group, the levels were still lower than those of the intact group. 1OHD administration resulted in no significant effect on weight gain, uterine weight, bone growth, bone length, or the cross sectional bone area compared with HX rats. However, the BMC and BMD were improved by $1 \mathrm{OHD}$ administration compared with the HX group. The levels were still lower than the intact control group. The combined intervention of GH and 1OHD in the HX rats did not result in any further improvement of the BMC or BMD when compared with the individual intervention.

Table 2 shows the results of static and dynamic histomorphometry of trabecular bone in the proximal tibial metaphysis. HX resulted in a significant decrease in the trabecular BV/TV and trabecular number, but an increase in the separation and osteoclast number per bone area compared with the intact group. Although, $1 \mathrm{OHD}, \mathrm{GH}$, or the $1 \mathrm{OHD}+\mathrm{GH}$ treatment, respectively, resulted in a significant increase in the BV/TV and a decrease in the separation compared with the HX group, 
Table 1. Body weight, uterine weight, proximal tibial longitudinal growth rate, femoral length, femoral bone area, bone mineral content, and the bone density

\begin{tabular}{|c|c|c|c|c|c|c|c|c|}
\hline & \multirow[b]{2}{*}{$\begin{array}{l}\text { Initial body } \\
\text { weight (g) }\end{array}$} & \multirow[b]{2}{*}{$\begin{array}{l}\text { Final body } \\
\text { weight (g) }\end{array}$} & \multirow{2}{*}{$\begin{array}{c}\text { Uterine } \\
\text { weight } \\
(\mathrm{mg})\end{array}$} & \multirow[b]{2}{*}{$\begin{array}{l}\text { Proximal tibial } \\
\text { LGR (mcm/day) }\end{array}$} & \multirow[b]{2}{*}{$\begin{array}{l}\text { Femoral length } \\
(\mathrm{mm})\end{array}$} & \multicolumn{3}{|c|}{ Femoral } \\
\hline & & & & & & $\begin{array}{l}\text { Bone area } \\
\left(\mathrm{cm}^{2}\right)\end{array}$ & BMC (mg) & $\begin{array}{c}\mathrm{BMD} \\
\left(\mathrm{mg} / \mathrm{cm}^{2}\right)\end{array}$ \\
\hline INTACT & $192 \pm 7.7$ & $255 \pm 18.3$ & $544 \pm 89$ & $17.3 \pm 0.71$ & $34.2 \pm 0.65$ & $1.52 \pm 0.09$ & $341 \pm 25$ & $223 \pm 7.13$ \\
\hline $\mathrm{HX}$ & $190 \pm 7.5$ & $189 \pm 12.2 *$ & $184 \pm 34 *$ & $1.33 \pm 0.42 *$ & $31.9 \pm 0.44 *$ & $1.29 \pm 0.07 *$ & $235 \pm 18 *$ & $181.7 \pm 6.29 *$ \\
\hline $\mathrm{HX}+1 \mathrm{OHD}$ & $193 \pm 6.7$ & $186 \pm 12.5^{*}$ & $191 \pm 29 *$ & $1.84 \pm 0.57 *$ & $31.5 \pm 0.62 *$ & $1.34 \pm 0.06^{*}$ & $265 \pm 22 * \dagger$ & $198 \pm 9.2 * \dagger$ \\
\hline $\mathrm{HX}+\mathrm{GH}$ & $190 \pm 10.8$ & $253 \pm 19.7 \dagger \div$ & $225 \pm 30^{*}$ & $16.8 \pm 0.87 \dagger \div$ & $34.0 \pm 1.03 \dagger 屯$ & $1.48 \pm 0.07 \dagger \ddagger$ & $313 \pm 17 * \dagger+$ & $207 \pm 7.25 * \dagger \ddagger$ \\
\hline $\begin{array}{l}\mathrm{HX}+1 \mathrm{OHD} \\
\quad+\mathrm{GH}\end{array}$ & $197 \pm 4.9$ & $269 \pm 13.7 \dagger \dagger$ & $201 \pm 37^{*}$ & $15.5 \pm 0.65^{* \dagger \dagger}$ & $34.3 \pm 0.66 \dagger+$ & $1.54 \pm 0.06+\div$ & $307 \pm 16^{*} \dagger+$ & $201 \pm 7.31 * \dagger$ \\
\hline
\end{tabular}

Data are expressed as mean \pm SD. One-Way ANOVA with Tukey Comparison test was used to compare the data among groups.

* Significant vs INTACT.

$\dagger$ Significant vs HX.

\$ Significant vs $\mathrm{HX}+1 \mathrm{OHD}$.

Table 2. Static and dynamic histomorphometry of trabecular bone in the proximal tibial metaphysis of the experimental groups

\begin{tabular}{|c|c|c|c|c|c|c|c|c|}
\hline & \multicolumn{8}{|c|}{ Trabecular } \\
\hline & $\begin{array}{l}\text { Bone Area } \\
(\mathrm{BV} / \mathrm{TV})(\%)\end{array}$ & $\begin{array}{l}\text { Thickness } \\
(\mathrm{mcm})\end{array}$ & Number (\#) & $\begin{array}{l}\text { Separation } \\
(\mathrm{mcm})\end{array}$ & $\begin{array}{c}\text { MAR } \\
\text { (mcm/day) }\end{array}$ & MS/BS (\%) & $\begin{array}{c}\mathrm{BFR} / \mathrm{BS} \\
\left(\mathrm{mcm}^{3} / \mathrm{mcm}^{2} /\right. \\
\text { day })\end{array}$ & $\begin{array}{l}\mathrm{NOc} / \mathrm{Bar} \\
\left(\# / \mathrm{mm}^{2}\right)\end{array}$ \\
\hline INTACT & $26.5 \pm 4.37$ & $53.5 \pm 3.97$ & $3.52 \pm 0.82$ & $388 \pm 36$ & $1.67 \pm 0.23$ & $21.8 \pm 6.03$ & $36.4 \pm 7.9$ & $33.6 \pm 10.4$ \\
\hline HX & $3.75 \pm 1.64^{*}$ & $55.8 \pm 6.01$ & $0.83 \pm 0.28 *$ & $1848 \pm 642 *$ & $1.75 \pm 0.13$ & $27.7 \pm 5.66$ & $49.0 \pm 12.6$ & $55.3 \pm 11.6^{*}$ \\
\hline $\mathrm{HX}+1 \mathrm{OHD}$ & $9.29 \pm 3.65^{* \dagger}$ & $62.6 \pm 5.86^{*}$ & $1.46 \pm 0.47 *$ & $1029 \pm 510^{* \dagger}$ & $1.70 \pm 0.2$ & $12.0 \pm 3.05^{* \dagger}$ & $20.6 \pm 6.1 * \dagger$ & $30.7 \pm 9.2 \dagger$ \\
\hline $\mathrm{HX}+\mathrm{GH}$ & $7.97 \pm 1.96 * \dagger$ & $49.4 \pm 8.53$ & $1.61 \pm 0.26^{* \dagger}$ & $1042 \pm 145^{* \dagger}$ & $2.27 \pm 0.36^{* \dagger+}$ & $32.4 \pm 7.11^{*} \neq$ & $74.1 \pm 11.8^{* \dagger} \ddagger$ & $49.1 \pm 9.5^{*}+$ \\
\hline $\mathrm{HX}+1 \mathrm{OHD}+\mathrm{GH}$ & $9.32 \pm 3.11 * \dagger$ & $56.1 \pm 4.34$ & $1.69 \pm 0.68 * \dagger$ & $866 \pm 281 \dagger$ & $2.13 \pm 0.20 * \dagger+$ & $23.0 \pm 4.2 \ddagger \S$ & $48.9 \pm 10.5 \ddagger \S$ & $39.9 \pm 10.9 \dagger$ \\
\hline
\end{tabular}

NOc/Bar, Osteoclast number per bone area.

* Significant $v s$ INTACT.

$\dagger$ Significant $v s$ HX.

\$ Significant $v s \mathrm{HX}+1 \mathrm{OHD}$.

$\S$ Significant $v s \mathrm{HX}+\mathrm{GH}$.

Data are expressed as mean \pm SD. One-way ANOVA with Tukey Comparison test was used to compare the data among groups.

Table 3. Static and Dynamic Histomorphometry of Cortical Bone in the Cross Section Proximal to the Tibia-Fibular Junction of the Experimental Groups

\begin{tabular}{|c|c|c|c|c|c|c|c|c|}
\hline & \multicolumn{4}{|c|}{ Periosteal bone surface } & \multicolumn{4}{|c|}{ Endocortical bone surface } \\
\hline & $\begin{array}{c}\text { Cortical Area } \\
(\%)\end{array}$ & $\begin{array}{c}\text { MAR } \\
\text { (mcm/day) }\end{array}$ & MS/BS (\%) & $\begin{array}{c}\mathrm{BFR} / \mathrm{BS} \\
\mathrm{mcm}^{3} / \mathrm{mcm}^{2} / \\
\text { day }\end{array}$ & $\begin{array}{c}\text { MAR } \\
\text { (mcm/day) }\end{array}$ & MS/BS (\%) & $\begin{array}{c}\mathrm{BFR} / \mathrm{BS} \\
\mathrm{mcm}^{3} / \mathrm{mcm}^{2} / \text { day }\end{array}$ & ES/BS (\%) \\
\hline INTACT & $82.3 \pm 1.77$ & $2.78 \pm 0.28$ & $75.8 \pm 9.7$ & $210 \pm 29.3$ & $1.45 \pm 0.21$ & $25.3 \pm 7.10$ & $36.7 \pm 23.13$ & $3.26 \pm 1.19$ \\
\hline HX & $81.5 \pm 1.81$ & $1.02 \pm 0.30 *$ & $8.9 \pm 4.14^{*}$ & $9.71 \pm 6.56^{*}$ & $1.42 \pm 0.31$ & $36.7 \pm 8.02$ & $54.3 \pm 32.1$ & $7.41 \pm 1.34 *$ \\
\hline $\mathrm{HX}+1 \mathrm{OHD}$ & $83.1 \pm 1.61$ & $0.89 \pm 0.45^{*}$ & $6.3 \pm 3.32 *$ & $6.79 \pm 6.16^{*}$ & $1.30 \pm 0.47$ & $31.7 \pm 9.88$ & $43.94 \pm 23.12$ & $5.19 \pm 0.66^{* \dagger}$ \\
\hline $\mathrm{HX}+\mathrm{GH}$ & $85.4 \pm 1.89 * \dagger \neq$ & $3.17 \pm 0.68 \dagger+$ & $90.9 \pm 3.8 * \dagger+$ & $288 \pm 64.5^{* \dagger \neq}$ & $1.65 \pm 0.34$ & $56.3 \pm 11.62 * \dagger \neq$ & $97.58 \pm 32.9 * \dagger+$ & $7.24 \pm 2.15^{*}+$ \\
\hline $\mathrm{HX}+1 \mathrm{OHD}+\mathrm{GH}$ & $84.1 \pm 1.50 \dagger$ & $3.41 \pm 0.65 \dagger \dagger$ & $78.8 \pm 6.7 * \dagger \dagger$ & $269 \pm 59.5^{* \dagger \neq}$ & $2.17 \pm 0.58^{* \dagger \ddagger \S}$ & $27.4 \pm 10.76 \S$ & $61.22 \pm 31.27 \S$ & $4.83 \pm 1.39 \dagger \S$ \\
\hline
\end{tabular}

Data are expressed as mean \pm SD. One-Way ANOVA with Tukey Comparison test was used to compare the data among groups.

* Significant $v s$ INTACT.

$\dagger$ Significant vs HX.

\$ Significant $v s \mathrm{HX}+1 \mathrm{OHD}$.

$\S$ Significant $v s \mathrm{HX}+\mathrm{GH}$.

none of the levels reach to those of the intact group. 1OHD treatment resulted in a significant decrease in the MS/BS, $\mathrm{BFR} / \mathrm{BS}$, and the osteoclast number, whereas GH treatment resulted in a significant increase in the MAR, MS/BS, and BFR/BS compared with the HX group. The result of $1 \mathrm{OHD}+$ GH treatment shows that the BFR/BS was higher than 1OHD group, but lower than the GH group, and osteoclast number was lower than the HX group.

Although the tibial cross-sectional total bone area $\left(\mathrm{cm}^{2}\right)$ of the HX was significantly lower than those of the intact rats (data not shown), the decrease in cortical area $\%$ was not statistically significant (Table 3). Administration of 1OHD alone to the HX rats did not increase cortical area \% significantly. GH administration to the HX rats with and without 1OHD resulted in a significant increase in cortical area $\%$.

Dynamic histomorphometry shows that HX resulted in a cessation of the periosteal MAR, MS/BS, BFR/BS, and an increase in the endocortical ES/BS compared with the intact group. Compared with the HX group, 1OHD had no significant effect on the periosteal or endocortical bone formation parameters, but a suppression of the endocortical ES/BS and GH increased both periosteal and endocortical MAR, MS/BS, 


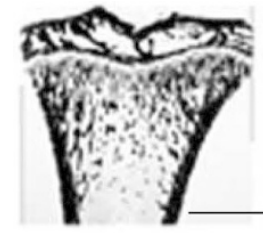

INTACT

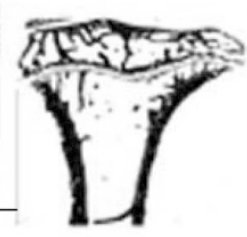

$\mathrm{HX}$

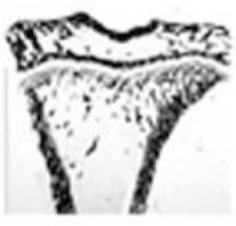

$\mathrm{HX}+\mathrm{GH}$

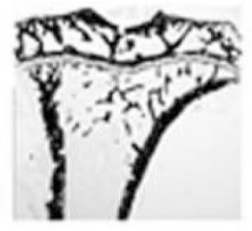

$\mathrm{HX}+1 \mathrm{OHD}$

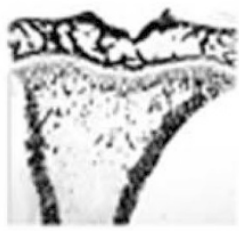

$\mathrm{HX}+\mathrm{GH}+1 \mathrm{OHD}$

Figure 1. Photomicrograph of proximal tibial metaphysis to show the growth plate, primary and secondary spongiosas in intact, $\mathrm{HX}, \mathrm{HX}+\mathrm{GH}, \mathrm{HX}+1 \mathrm{OHD}$, and $\mathrm{HX}+\mathrm{GH}+1 \mathrm{OHD}$ rats from the 4-wk study. Notice the loss of trabecular bone mass and growth plate width after the HX; growth hormone administration activated growth plate formation and trabecular bone mass in the primary and secondary spongiosa.

BFR/BS without a significant effect on endocortical ES/BS. The combined intervention of $1 \mathrm{OHD}+\mathrm{GH}$ did not result in any further increase in periosteal BFR/BS, but did result in a decrease in the endocortical BFR/BS and ES/BS compared with the $\mathrm{HX}+\mathrm{GH}$ group.

Figure 1 is a photomicrograph of proximal tibial metaphysis showing the growth plate, primary and secondary spongiosa in intact, $\mathrm{HX}, \mathrm{HX}+\mathrm{GH}, \mathrm{HX}+1 \mathrm{OHD}$, and $\mathrm{HX}+\mathrm{GH}+1 \mathrm{OHD}$ rats from the 4-wk study. Although the histologic changes were not assessed quantitatively, hypophysectomy appeared to result in decrease in trabecular bone mass and growth plate width. Growth hormone administration appeared to increase growth plate width and bone volume in the primary and secondary spongiosa areas. 1OHD administration prevented trabecular bone loss in the secondary spongiosa.

\section{DISCUSSION}

The main purpose of this study was to determine whether the administration of GH and 1OHD together had a more beneficial effect on the long bones in $\mathrm{HX}$ rats than the administration of either agent alone. Our results confirm our previous findings that $\mathrm{HX}$ not only results in cessation of bone growth in length, circumference, and size but also results in a significant decrease in BMC and BMD $(25,26)$. It also confirms that GH treatment completely prevented the loss of cortical bone mass by markedly increasing periosteal bone formation, ameliorating the increase of endocortical bone turnover, increasing the femoral bone length, and femoral bone area in $\mathrm{HX}$ rats and improved the femoral BMC and $\mathrm{BMD}$, but not to the extent as in intact control and was unable to fully restore the trabecular bone mass as evident by the histomorphometric data (3).

It is well known that there is a difference in bone growth, modeling, and remodeling in cortical and trabecular bone. Typically, bone growth and modeling improves new bone formation on the bone surface without prior resorption, whereas bone remodeling either conserves or removes the bone in contact with the marrow cavity. In young growing rats, periosteal and new bone formation occurs in the primary spongiosa beneath the growth plate without prior resorption and mainly undergoes modeling, whereas bone remodeling predominates at the trabecular and endocortical surface area. Thus, the findings that GH increased periosteal bone formation, longitudinal growth, and new bone formation beneath the growth plate suggests that GH may enhance bone growth and new bone formation through the activation of bone modeling in HX rats. Therefore, the partial increase in trabecular $\mathrm{BV} / \mathrm{TV} \%$ measured in the secondary spongiosa after $\mathrm{GH}$ treatment could be mediated by the increase in chondrocyte elongation and the new bone expansion. Conversely, GH increases metaphyseal trabecular and endocortical bone formation without enhancing resorption, as measured by the osteoclast cell number per bone area and erosion surface indicating that growth hormone increases net bone formation at both sites that predominantly undergo coupled formation and resorption in the skeleton in the HX rats. Consequently, the use of agents with antiresorptive properties in combination with anabolic agent like GH should be helpful in enhancing the net bone formation, and antiresorptive agent would be helpful in suppressing bone resorption, although improving the net bone gain (33-37). Results of bone density, trabecular and cortical bone mass, and the dynamic histomorphometry of the current study demonstrate that the combined intervention of GH and 1OHD has a benefit of increasing bone growth, elongation, and also preventing bone loss better than the treatment with either agent alone in the animals with pituitary hormone deficiency.

Different groups have published comparison studies with GH and other anabolic agents like PTH and antiresorptive agents like estrogens, bisphosphonates in HX animal models, but these combinations failed to fully restore the trabecular bone to the level of intact animals (26-30). There are several reports about the antiresorptive action of 1OHD on bone metabolism on OVX rat models; there are also reports about the anabolic actions of this metabolite (37-41). Iwamoto et al. and $\mathrm{Li}$ et al. observed an antiresorptive action of 1OHD in aged OVX Sprague-Dawley model when using a low dose $(0.05-0.1 \mu \mathrm{g} / \mathrm{kg})$ whereas an anabolic action occurred if the dosage was increased to $0.15-0.2 \mu \mathrm{g} / \mathrm{kg}$ or higher $(38-40)$. In our study, the dose of 1 OHD used was $0.25 \mu \mathrm{g} / \mathrm{kg} / \mathrm{d}$, equivalent to the range of high dose used by $\mathrm{Li}$ et al. and Iwamoto et al., yet, we did not observe enhancement in the bone formation, including MAR, MS/BS, and BFR/BS, in HX rats. Instead, what we did observe was a decrease in the endocortical ES/BS in cortical bone and decrease in osteoclast number per bone area in the cancellous bone. This demonstrated only the antiresorptive action in our HX rat model. This discrepancy in the actions of 1OHD observed in our model could be due to lack of other pituitary hormone in HX rats, differences in the age and type of animal model, or a dosage effect. 
As expected, our current data demonstrates that without GH, 1OHD treatment alone has no effect on femoral length, proximal tibial longitudinal growth, and periosteal BFR. 1OHD treatment does, however, suppress the endocortical resorption and trabecular bone turnover, and hence improving the BMC and BMD suggesting that the effect of 1OHD in the HX rats is suppression of bone remodeling. The beneficial effect of 1OHD on bone could be secondary to increase in intestinal calcium absorption and changes in PTH because D-hormone can reduce serum PTH levels (16) and block parathyroid gland proliferation and secretion $(42,43)$. Conversely, there is also evidence that $1 \mathrm{OHD}$ could have direct suppression of osteoclastogenesis in vivo by decreasing the pool of osteoclast precursors in bone marrow (44). It has also been proven in parathyroidectomized rats under constant PTH infusion that 1OHD exerts a direct anabolic effect on bone mass independent of calcium absorption and PTH suppression (37). The current finding of suppressive effect of 1OHD on bone resorption in the HX rats could be because of both direct and indirect effect.

The results of our study demonstrated that the group given the combination of $\mathrm{GH}$ and $1 \mathrm{OHD}$, the improvement in the cortical area \% and absolute cortical area in size are mediated primarily by $\mathrm{GH}$, stimulating periosteal and endocortical bone formation rate. Whereas the group given just 1OHD, resulted in a decrease in endocortical and trabecular bone resorption, as indicated by the erosion surface and osteoclast number. However, the net bone gain ultimately was not better than either treatment alone.

In conclusion, the combination of GH and 1OHD treatment, the trabecular BV/TV and cortical area \% were not significantly improved. It appears that GH and $1 \mathrm{OHD}$ have a differential effect on bone metabolism. GH increases periosteal, endocortical, and trabecular bone formation rate. Although 1OHD had no effect on periosteal bone formation, but it did suppress the endocortical and trabecular bone turnover rate. Further studies are needed to assess the effects of different dosages of $1 \mathrm{OHD}$, in combination with $\mathrm{GH}$, on bone metabolism in young HX animals.

\section{REFERENCES}

1. Attanasio AF, Howell S, Bates PC, Frewer P, Chipman J, Blum WF, Shalet SM 2002 Body composition, IGF-1and IGFBP3 concentration as outcome measures in severely growth hormone deficient (GHD) patients after childhood GH treatment: a comparison with adult onset GHD patients. J Clin Endocrinol Metab 87:3368-3372

2. Fernholm R, Bramnert M, Hagg E, Hilding A, Baylink DJ, Mohan S, Thoren M 2000 Growth hormone replacement therapy improves body composition and increases bone metabolism in elderly patients with pituitary diasease. J Clin Endocrinol Metab $85: 4104-4112$

3. Chen MM, Yeh JK, Aloia JF 1997 Histological evidence: growth hormone completely prevents reduction in cortical bone gain and partially prevents cancellous osteopenia in the tibia of hypophysectomized rats. Anat Rec 249:163-172

4. Zhao G, Monier-Faugere MC, Langub MC, Geng Z, Nakayama T, Pike JW, Chernausek SD, Rosen CJ, Donahue LR, Malluche HH, Fagin JA, Clemens TL 2000 Targeted overexpression of insulin-like growth factor I to osteoblasts of transgenic mice: increased trabecular bone volume without increased osteoblast proliferation. Endocrinology 141:2674-2682

5. Daughaday WH 2000 Growth hormone axis overview-somatomedin hypothesis. Pediatr Nephrol 14:537-540

6. Zhang M, Xuan S, Bouxsein ML, Von Stechow D, Akeno N, Faugere MC, Malluche H, Zhao G, Rrosen CJ, Efstratiadis A, Clemens TL 2002 Osteoblast specific knockout of the insulin like growth factor (IGF) receptor gene reveals an essential role of igf signaling in bone matrix mineralization. J Biol Chem 277:44005-44012
7. Burstein S, Chen IW, Tsang RC 1983 Effects of growth hormone replacement therapy on 1-25 dihydroxy vitamin D and calcium metabolism. J Clin Endocrinol Metab 56:1246-1251

8. Wongsurawat N, Armbrecht HJ, Zenser TV, Forte LR, Davis BB 1984 Effects of hypophysectomy and growth hormone treatment on renal hydroxylation of 25 hydroxycholecalciferol in rats. J Endocrinol 101:333-338

9. Spencer EM, Tobiassen O 1981 The mechanism of action of growth hormone on vitamin D in the rats. Endocrinology 108:1064-1070

10. Wei S, Tanaka H, Kubo T, Ono T, Kanzaki S, Seino Y 1997 Growth hormone increases serum 1,25 dihydroxyvitamin D levels and decreases 24,25 dihydroxyvitamin D levels in children with growth hormone deficiency. Eur J Endocrinol $136: 45-51$

11. Langman CB, Mazur AT, Baon R, Norman ME 198225 Hydroxy vitamin D3 therapy of juvenile renal osteodysdrophy: beneficial effect on linear growth velocity. J Pediatr 100:815-820

12. Gray RW, Garthwaite TL 1985 Activation of renal 1,25-dihydroxyvitamin D3 synthesis by phosphate deprivation: evidence for a role for growth hormone. Endocrinology 116:189-193

13. Salusky IB, Goodman WG 1995 Growth hormone and calcitriol as modifiers of bone formation in renal osteodystrophy. Kidney Int 48:657-665

14. Johnson JA, Grande JP, Roche PC, Kumar R 1996 Ontogeny of the 1,25dihyroxyvitamin D3 Receptor in fetal rat bone. J Bone Miner Res 11:56-61

15. Mee AP, Hoyland JA, Braidman IP, Freemont AJ, Davies M, Mawer EB 1996 Demonstration of vitamin D receptor transcripts in actively resorbing osteoclasts in bone sections. Bone 18:295-299

16. Schacht E, Richy F, Reginster JY 2005 The therapeutic effects of alfacalcidol on bone strength, muscle metabolism and prevention of falls and fractures. J Musculoskelet Neuronal Interact 5:273-284

17. Chun RF, Adams JS, Hewison M 2008 Back to the future: a new look at "old" vitamin D. J Endocrinol 198:261-269

18. Erben RG, Brown S, Stangassinger M 1998 Therapeutic efficacy of $1 \alpha$, 25-dihyroxy vitamin D3 and calcium in osteopenic ovariectomized rats: evidence for a direct anabolic effect of $1 \alpha, 25$ dihyroxyvitamin D3 on bone. Endocrinology 139:43194328

19. Erben RG, Weiser H, Sinowatz F, Rambeck WA, Zucker H 1992 Vitamin D metabolites prevent vertebral osteopenia in ovariectomized rats. Calcif Tissue Int 50:228-236

20. Erben RG, Mosekilde L, Thomsen JS, Weber K, Stahr K, Smith SY, Phipps RJ 2001 Prevention of bone mass by combined treatment with risedronate and $1 \alpha, 25$ dihydroxy vitamin D3 in ovaiectomized rats. J Bone Miner Res 16:S530

21. Chen H, Tian X, Liu X, Setterberg RB, Li M, Jee WS 2008 Alfacalcidol-stimulated focal bone formation on the cancellous surface and increased bone formation on the periosteal surface of the lumbar vertebrae of adult female rats. Calcif Tissue Int 82:127-136

22. Finkelman RD, Linkhart TA, Mohan S, Lau KH, Baylink DJ, Bell NH 1991 Vitamin $\mathrm{D}$ deficiency causes a selective reduction in deposition of transforming growth factor beta in rat bone: possible mechanism for impaired osteoinduction. Proc Natl Acad Sci USA 88:3657-3660

23. Lau KH, Baylink DJ 2001 Treatment of 1,25(OH)2 D3 (D-hormone) deficiency/ resistance with D-hormone and analogs. Osteologie 10:28-39

24. Schacht E 1999 Rationale for treatment of involutional osteoporosis in women and for prevention and treatment of corticosteroid-induced osteoporosis with alfacalcidol. Calcif Tissue Int 65:317-327

25. Chen MM, Yeh JK, Aloia JF 1995 Skeletal alterations in hypophysectomized rats I. A histomorphometric study on tibial cancellous bone. Anat Rec 241:505-512

26. Chen MM, Yeh JK, Aloia JF 1995 Skeletal alterations in hypophysectomized rats. II. A histomorphometric study on tibial cortical bone. Anat Rec 241:513-518

27. Yeh JK, Chen MM, Aloia JF 1997 Effects of estrogen and growth hormone on skeleton in the ovariectomized rat with hypophysectomy. Am J Physiol 273:E734E742

28. Shiraishi A, Takeda S, Masaki T, Higuchi Y, Uchiyama Y, Kubodera N, Sato N, Ikeda K, Nakamura T, Matsumoto T, Ogata E 2000 Alphacalcidol inhibits bone resorption and stimulates formation in an ovariectomized rat model of osteoporosis: distinct actions from estrogen. J Bone Miner Research 15:770-779

29. Prakasam G, Yeh J, Chen M, Castro-Magana M, Liang C, Aloia J 1999 Effects of growth hormone and testosterone on cortical bone formation and bone density in aged orchectomized rats. Bone 24:491-497

30. Hock JM, Fonseca J 1990 Anabolic effect of human synthetic parathyroid hormone(1-34) depends on growth hormone. Endocrinology 127:1804-1810

31. Schmidt IU, Dobnig H, Turner R 1995 Intermittent parathyroid hormone treatment increases osteoblast number, steady state messenger ribonucleic acid level for osteocalcin, and bone formation in tibial metaphysis of hypophysectomized female rats. Endocrinology 136:5127-5134

32. Parfitt AM, Drezner MK, Glorieux FH, Kanis JA, Malluche H, Meunier PJ, Ott SM, Recker RR 1987 Bone histomorphometry: standardization of nomenclature, symbols and units. Report of the ASMBR Histomorphometry Nomenclature Committee. J Bone Miner Res 2:595-610

33. Cuneo RC, Judd S, Wallace JD, Perry-Keene D, Burger H, Lim-Tio S, Strauss B, Stockigt J, Topliss D, Alford F, Hew L, Bode H, Conway A, Handelsman D, Dunn S, Boyages S, Cheung NW, Hurley D 1998 The Australian multicenter trial of growth hormone $(\mathrm{GH})$ treatment in $\mathrm{GH}$ deficient adults. J Clin Endocrinol Metab 83:107-116

34. Frost HM 2000 Growth hormone and osteoporosis: an overview of endocrinological and pharmacological insights from the Utah paragigm of skeletal physiology. Horm Res 54:36-43 
35. Krysiak R, Gdula-Dymek A, Bednarska-Czerwinska A, Okopien B 2007 Growth hormone therapy in children and adults. Pharmacol Rep 59:500-516

36. Tonshoff B, Heinrich U, Mehls O 1991 How safe is the treatment of uremic children with recombinant human growth hormone. Pediatr Nephrol 5:454-460

37. Shiraishi A, Higashi S, Ohkawa H, Kubodera N, Hirasawa T, Ezawa I, Ikeda K, Ogata E 1999 The advantage of alpha calcidol over vitamin D in the treatment of osteoporosis. Calcif Tissue Int 65:311-316

38. Iwamoto J, Seki A, Takeda T, Yamada H, Sato Y, Yeh JK 2007 Effects of alfacalcidol on cancellous and cortical bone mass in rats treated with glucocorticoid: a bone histomorphometry study. J Nutr Sci Vitaminol (Tokyo) 53:191-197

39. Li M, Li Y, Healy DR, Simmons HA, Ke HZ, Thompson DD 2003 Alfacalcidol restores cancellous bone in ovariectomized rats. J Musculoskelet Neuronal Interact $3: 39-46$

40. Iwamoto J, Seki A, Takeda T, Sato Y, Yamada H, Yeh JK 2006 Effect of risedronate on cancellous and cortical bone mass and mechanical properties in ovariectomized rats: a comparison with the effects of alfacalcidol. J Nutr Sci Vitaminol (Tokyo) 52:393-401

41. Iwamoto J, Seki A, Takeda T, Sato Y, Yamada H, Yeh JK 2006 Effects of alendronate and alfacalcidol on cancellous and cortical bone mass and bone mechanical properties in ovariectomized rats. Exp Anim 55:357-367

42. Szabo A, Merke J, Beier E, Mall G, Ritz E 1989 1,25 (OH)2Vitamin D3 inhibits parathyroid cell proliferation in experimental uremia. Kidney Int 35:1049-1056

43. Brown AJ, Ritter CS, Knutson JC, Strugnell SA 2006 The vitamin D prodrugs $1 \alpha(\mathrm{OH}) \mathrm{D} 3$ and $\mathrm{BCI}-210$ suppress PTH secretion by bovine parathyroid cells. Nephrol Dial Transplant 21:644-650

44. Shibata T, Shira-Ishi A, Sato T, Masaki T, Sasaki A, Masuda Y, Hishiya A, Ishikura N, Higashi S, Uchida Y, Saito M, Ito M, Ogata E, Watanabe K, Ikeda K 2002 Vitamin D hormone inhibits osteoclastogenesis in vivo by decreasing the pool of osteoclast precursors in bone marrow. J Bone Miner Res 17:622-629 